\title{
Analytical Method Validation of Lauric Acid Present in Pure and Commercial Preparations of Coconut Oil using GC-FID Method
}

\author{
Tatineni Spandana \\ Department of Pharmaceutical Chemistry \\ JSS College of Pharmacy, \\ JSS Academy of Higher Education and Research, \\ Shivarathreeshwara Nagar, Bannimantap, \\ Mysuru - 570015, Karnataka, India
}

\author{
Dr. B. M. Gurupadayya \\ Professor \\ Coordinator-M.Pharm Pharmaceutical Analysis \\ Dept. of Pharmaceutical Chemistry, \\ JSS College of Pharmacy, \\ JSS Academy of Higher Education and Research \\ Shivarathreeshwara Nagar, Bannimantap, \\ Mysuru- 570015, Karnataka, India.
}

\begin{abstract}
Lauric acid is the chief constituent of Cocos nucifera (coconut oil). The main objective of the study was to develop a simple, robust and derivatization free GC-FID method that is suitable for routine analysis of lauric acid in the pure and commercial coconut oil. The sample was dissolved in methanol and diluted. The solution was then injected in split mode to ZB-WAX plus column of length 30 $\mathrm{m}$, internal diameter of $0.25 \mathrm{~mm}$ ID and film thickness of 0.5 $\mu \mathrm{m}$. The retention time of lauric acid was found to be 6.42 min.The method showed possibility to detect the standard solutions of lauric acid with a linear determination in the range of $100-500 \mathrm{mcg} / \mathrm{mL}$ with correlation coefficient (r) 0.9996. The limit of detection and limit of quantitation were found to be 0.385 and 1.168 respectively. The method showed good accuracy and precision for both interday and intraday with \% RSD $<2 \%$. This method can be employed for the estimation of lauric acid in various commercial oils present in the market.
\end{abstract}

Key Words: Lauric acid, Cocos nucifera, GC-FID and Analytical method validation.

\section{INTRODUCTION:}

Lauric Acid is a saturated medium chain fatty acid with a 12 carbon backbone. It is chemically Dodecanoic acid. Lauric acid is found naturally in various plant and animal fats and oils, and is a major component of coconut oil and palm kernel oil. In Palm kernel oil lauric acid acts as an antimicrobial agent (Moigradean et al., 2013) it contains major fatty acids oleic acid $(\mathrm{C} 18,15 \%)$,lauric acid(C12, $48 \%$ ), myristic acid (C14, 16\%)(Onyeagba and Chigbu, 2006). Coconut oil is a vegetable oil is obtained from the nut of the palm tree, Cocos nucifera L. Refined coconut oil (RCO) is produced by oil extraction from dried copra, followed by bleaching, deodorization and chemical refinement. Virgin coconut oil (VCO), is produced from the fresh mature coconut meat and is processed by mechanical and natural processes (FABIAN M. DAYRIT,* OLIVIA ERIN M. BUENAFE, EDWARD T. CHAINANI and Department, 2008). It has actibacterial activity (Loung, Silalahi and Suryanto, 2015)VCO contains high lauric acid content (46-50\%) attached to glycerol backbone to form a triglyceride (Silalahi and Putra, 2018). Lauric acid adds to the improvement of HDL level in the body (Denke and Grundv, 2018)there by helps in depletes the cholesterol level in the body (Elisabeth and HM Temme, Ronald $\mathrm{P}$ Mensink, 2018; Thoistrup et al., 2018). It promotes ketosis and have antioxidant activity, which is helpful for people on low- ketogenic and carbohydrate diets and uplift the destruction of malignant tumor cells and prevent the growth of cancer, particularly in colon cancer cells and breast cancer. It decreases heart rate, blood pressure blood pressure, oxidative stress, heart rate in kidneys and heart. It conflicts several types of infective microbes and able to fight with food borne pathogens by the conjugation with essential oils. It is even given to animals in their feed in order to improve food safety and meat quality. Lauric acid extracted from coconut oil contains monolaurin. Monolaurin is an antimicrobial agent that is able to fight bacteria, viruses, yeasts, and other pathogens (Enig, 1996). Lauric acid is also employed in various cosmetic preparations. As Lauric acid has wide applications in cosmetics and pharmaceuticals various methods are developed for its quantification from its various sources. Various Gas Chromatographic methods are already developed for the general quantification of fatty acids. A gas chromatography-flame ionization detection (GC-FID) method was developed for analysis of oleic acid (Zhang, Wang and Liu, 2015).

Literature studies revealed that there were no methods developed for the determination and estimation of Lauric acid in coconut oil using GC-FID method. So we developed a derivatization free GC-FID method for the quantification of lauric acid in coconut oil and validated the method according to $\mathrm{ICH}$ guidelines.

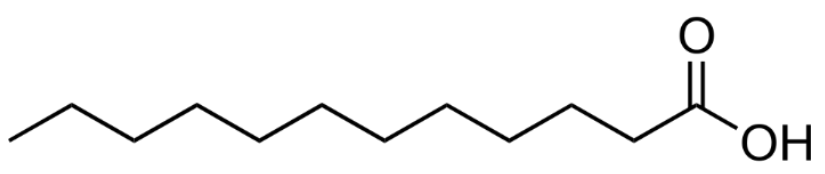

Fig 1 (Structure of Lauric acid)

Lauric acid has been known as one of the most active ingredient and made up of $52 \%$ of the total $92 \%$ saturated fats present in the coconut oil((Division and Associates, 2002)and is claimed to play a significant role in the healing miracle that is revealed in coconut oil((Dayrit, 2014)) that 
is it lowers the cholesterol level. Ingestion of coconut oil containing high amount of lauric acid increases the saturated fatty acids which simultaneously increases the human milk (Francois et al., 2018)).Virgin coconut oil, a potent nondrug or natural yeast fighter, consists of three medium chain fatty acids, i.e. lauric acid (50\% to 53\%), capric acid and caprylic acid, all of which have antifungal and antibacterial effect against bacteria which is coated with lipid and fungi such as Candida spp. Medium-chain free fatty acids have been found to have a wide range of microbicidal activity (Shilling et al., 2013)) though the mechanisms by which the lipids kill bacteria is not known, but electron microscope studies indicate that they disrupt cell membranes. On the other hand, free fatty acids (FFA) of various chain lengths (C8- C18) have wide range of antibacterial activity against Grampositive bacteria ((Dayrit, 2014)), but not against Gram-negative bacteria (Anzaku et al., 2017)). Lauric acid contains less amount of sebum component ( $1 \%$ to $2 \%$ of total sebum FFA), but it is the most active antimicrobial FFA (Elisabeth and HM Temme, Ronald P Mensink, 2018))(Anzaku et al., 2017). The esterification of coconut oil which yielded a carbon chain has proved beyond reasonable doubt that, lauric acid 12-carbon chain fatty acid is more biological active than coconut oil which is the parent substance and has the highest antiviral activities (St et al., 1988; Bornscheuer, 1995)This resulted from the medium chain triglycerides (MCTs) which have anti-bacterial influence present in coconut oil because it has the ability to disintegrate bacterial cell walls; MCTs also have the ability to treat severe bacterial infections that are antibiotic resistant. This lauric acid is used for the treatment of bacterial infections, viral infections, protozoal infections and fungal infection and it is used for the production of cosmetics and soap as, it neutralizes with sodium hydroxide $(\mathrm{NaOH})$ and give sodium laurate by saponification ((Anzaku et al., 2017)). Some previous studies demonstrated that lauric acid (sodium laurate) has antimicrobial efficacy against both multispecies biofilms and E. faecalis biofilms. Several claims have been made on the use of lauric acid and its parent substance coconut oil on its medicinal effect and health benefits. This study therefore aimed at investigating the invitro microbicidal effect of lauric acid on some clinical isolates. Recent isolates of bacterial organisms were isolated from clinical specimens of patients with respiratory tract infection, digestive tract infection and urinary tract infection attending health care facilities at the General Hospital Maitama ((Anzaku et al., 2017))

\section{OTHER METHODS FOR ESTIMATION OF LAURIC ACID:-}

A Method was developed to analyze lauric acid (LA), monolaurin (ML), dilaurin (DL), and trilaurin (TL) by gas chromatography - flame ionization detector (GC-FID) and high performance liquid chromatography - evaporative light scattering detector (HPLC-ELSD) in MCO samples. This method is developed to compare and optimize HPLCELSD and GC-FID methods for determination of LA, ML, DL, and TL in MCO samples. GC-FID exhibits good linearity, sensitivity and has satisfactory recoveries of LA analysis. Whereas HPLC-ELSD exhibits good linearity, sensitivity and acceptable recoveries for TA analysis. Both methods were applied to determine the MCO samples produced under varied conditions for glycerolysis. The results revealed that the developed HPLC-ELSD method is appropriate for the determination of ML, DL, and TL while the developed GC-FID method is suitable for the quantification of LA, ML, and DL. Both developed GCFID and HPLC-ELSD methods produced reproducible results in MCO samples for the determination of LA, ML, DL, and TL in ((Ponphaiboon et al., 2018)).

Another derivatization procedure is described for the long chain fatty acid that is lauric acid and metabolites using the fluorescent pmbe 4-(bmmomethyl)-7- methoxycoumarin. The derivatives can be separated in an isocratic high performance liquid chromatographic system and detected using a fluorescence detector. The derivatization gives a good quantitation by the use of an internal standard and it is rapid and simple. The procedure has been applied on samples rat liver homogenates with the plasticizer di (2ethylhexy1) phthalate. The activity of cytochrome P-450 IVAl or lauric acid hydroxylase \&AH) in liver homogenates can be determined by the determination of the 11- and 1Zhydroxylated metabolites of lauric acid. The method was found to be suitable and sensitive to replace similar assays using radioactive compounds ((Jansen and Flutter, no date))

Other method was also developed for the isolation of lauric acid from crude coconut oil through the, base transesterification using methanol, neutralization of the free fatty acid, fractional distillation of the methyl ester mixture, and base hydrolysis of methyl laurate ((Odel, Siswanta and Nurwening, 2016).

Another method is to identify the fatty acid composition of two different vegetables oils (walnut and coconut oils) by gas chromatography-mass spectrometry (GC-MS) method. The results showed that the predominant fatty acids identified of coconut oil are lauric acid (44.6\%) and myristic acid (20.4\%) ((Moigradean et al., 2013)).

\section{Objective:}

The main objective of the study was to develop a simple, robust and derivatization free GC-FID method that is suitable for routine analysis of lauric acid in the pure and commercial coconut oil.

\section{MATERIALS AND METHOD: REAGENTS AND CHEMICALS:}

All the reagents used in the studies were analytical reagent (AR) graded and few are HPLC graded. Standard grade of lauric acid was procured from Sigma .Sodium hydroxide and methanol were obtained from Merck (Damstadt, Germany). Pure coconut oil was obtained from a local coconut oil mill (Kerala).

\section{GAS CHROMATOGRAPHY ANALYSIS:}

Gas chromatographic analysis were carried out on model GC2014, Shimadzu, Gas Chromatograph(Shimadzu, Japan) equipped with a split/split less capillary injector and flame ionization detector. ZB-WAX plus capillary column $(30 \mathrm{~m}$ $\mathrm{X} \quad 0.25 \mathrm{~mm}$ i.d.) with film thickness of $0.25 \mu \mathrm{m}$ 
(Phenomenex, Torance, USA). Nitrogen was used as carrier gas (with constant flow rate of $0.89 \mathrm{ml} / \mathrm{min}$ ).

The injector and detector temperature were set at 250 and $280^{\circ} \mathrm{C}$ respectively. The oven temperature was programmed as follows: initially $100^{\circ} \mathrm{C}$, which was raised to $150^{\circ} \mathrm{C}$ for $1 \mathrm{~min}$ with the rate of $25,150^{\circ} \mathrm{C}$ was raised to $220^{\circ} \mathrm{C}$ for 2 min with the rate of 20 and $220^{\circ} \mathrm{C}$ was raised to $230^{\circ} \mathrm{C}$ for $1 \mathrm{~min}$ at the rate of 20 . Peak area was employed for the determination of amount of lauric acid present.

\section{STANDARD SOLUTION PREPARATION:}

Stock was prepared by dissolving $100 \mathrm{mg}$ of lauric acid in methanol and the volume was made up to $100 \mathrm{ml}$ using the same solvent. Working standard were prepared by pipetting out $1,2,3,4$ and $5 \mathrm{ml}$ of the solution to $10 \mathrm{ml}$ volumetric flask and the volume was made up to the mark using methanol (100-500 $\mu \mathrm{g} / \mathrm{ml})$.

\section{SAMPLE PREPARATION:}

$10 \mathrm{gm}$ of pure coconut oil was extracted with methanol. Initially, $20 \mathrm{ml}$ of methanol was used and remaining $30 \mathrm{ml}$ of methanol was used to separate the lauric acid from the sample of oil exhaustively. The methanol layer was dried to get residues of lauric acid.

This residue was transferred to a beaker and $10 \mathrm{ml}$ of $10 \mathrm{~N}$ sodium hydroxide was added. The solution was boiled until the 2 layers become miscible in each other. The reaction mixture was cooled in order to separate layers of glycerol and lauric acid. Lauric acid crystallizes at room temperature. The crystals were separated and dried.

$100 \mathrm{mg}$ of the crystals were dissolved in methanol and volume was made up to $100 \mathrm{ml}$ using methanol. Further, dilutions were made to get the concentration in the linear range. $1 \mu \mathrm{l}$ volume of the above solution was filtered and was analyzed by gas chromatography.

\section{RESULTS AND DISCUSSION:}

\section{Method development:}

The aim of the study was to develop a simple, robust and derivatization free method for the analysis of lauric acid present in coconut oil.

A systemic method development strategy was employed. The strategy involves the selection of solvent, selection of column, determination of sample concentration, determination of injection parameter and temperature programming were carried out to get an optimized method. As lauric acid has a short chain of hydrocarbon polar solvents like methanol can be employed in the study. Polarity of column stationary phase plays a critical role in the separation of fatty acids. The polarity of lauric acid is in close match with the polyethylene glycol. Hence ZBWAX plus column whose stationary phase in polyethylene glycol employed in the study.

Concentration was determined by initially injecting the column with $1000 \mu \mathrm{g} / \mathrm{ml}$ of lauric acid, which showed higher peak area. Later the column was injected with $10 \mu \mathrm{g} / \mathrm{ml}$ which showed no peaks. Therefore concentration was increased to $100 \mu \mathrm{g} / \mathrm{ml}$ which showed a minimum peak area. Hence the concentration was set to 100-500 $\mu \mathrm{g} / \mathrm{ml}$.

Various injection parameters like inlet temperature, split ratio, pressure of gases, flow rate etc. were changed. A optimum parameter ranges were set up. Column temperature programming was carried out to improve the separation of lauric acid peak.

\section{VALIDATION:}

The proposed method was validated for accuracy, precision, robustness, linearity \& range and Limit of detection (LOD) \& Limit of quantitation (LOQ) as per ICH guidelines for method validation.

\section{LINEARITY \& RANGE:}

The correlation coefficient of lauric acid standard was evaluated in the range of $100-500 \mu \mathrm{g} / \mathrm{ml}$. the results were found to be linear and are shown in Table 1.overlay spectra of lauric acid is shown in Fig. 1 and the linearity graph is shown in Fig.2

Fig.2: Overlay Chromatograph of Lauric acid

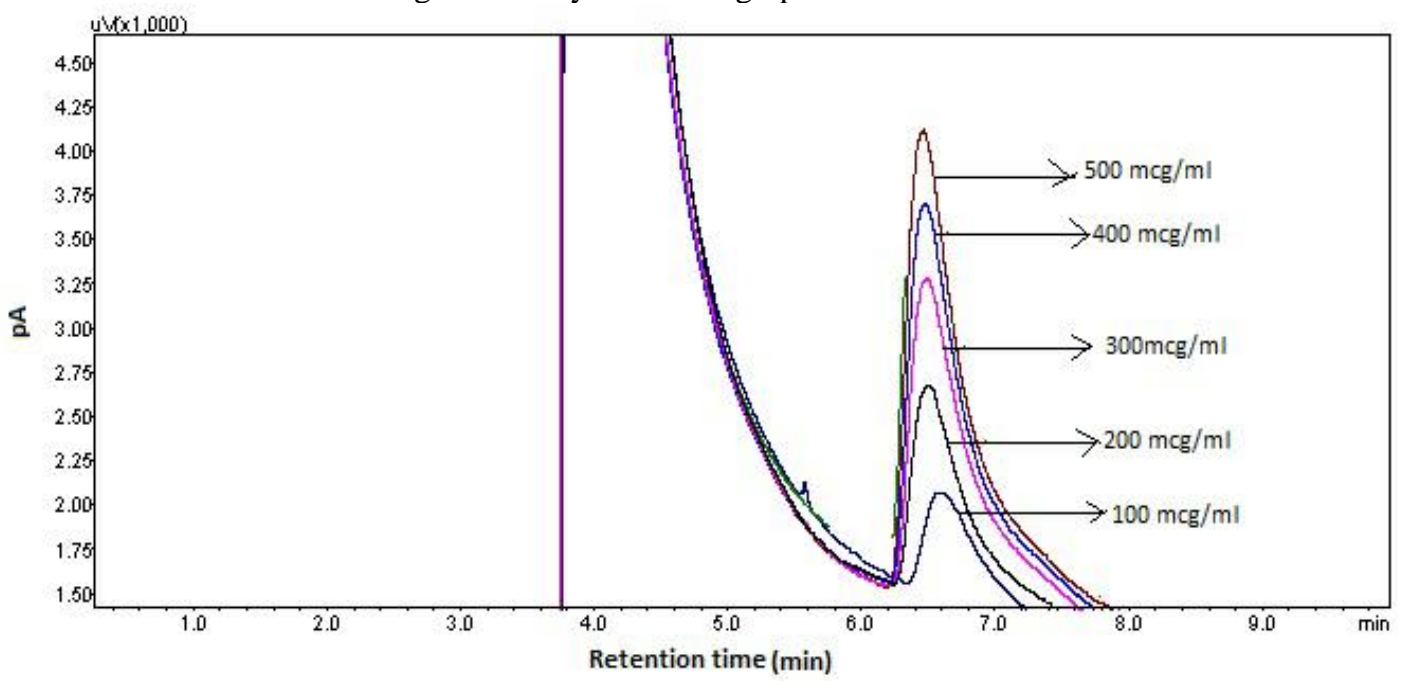


Table 1: Concentration V/s Peak Area for Linearity study

\begin{tabular}{|c|c|c|}
\hline SI.No & Concentration $(\boldsymbol{\mu g} / \mathbf{m l})$ & Peak Area \\
\hline 1 & 100 & 7854.2 \\
\hline 2 & 200 & 27091.0 \\
\hline 3 & 300 & 47873.3 \\
\hline 4 & 400 & 75553 \\
\hline 5 & 500 & 97216.9 \\
\hline
\end{tabular}

Fig.3: Linearity graph of Lauric acid

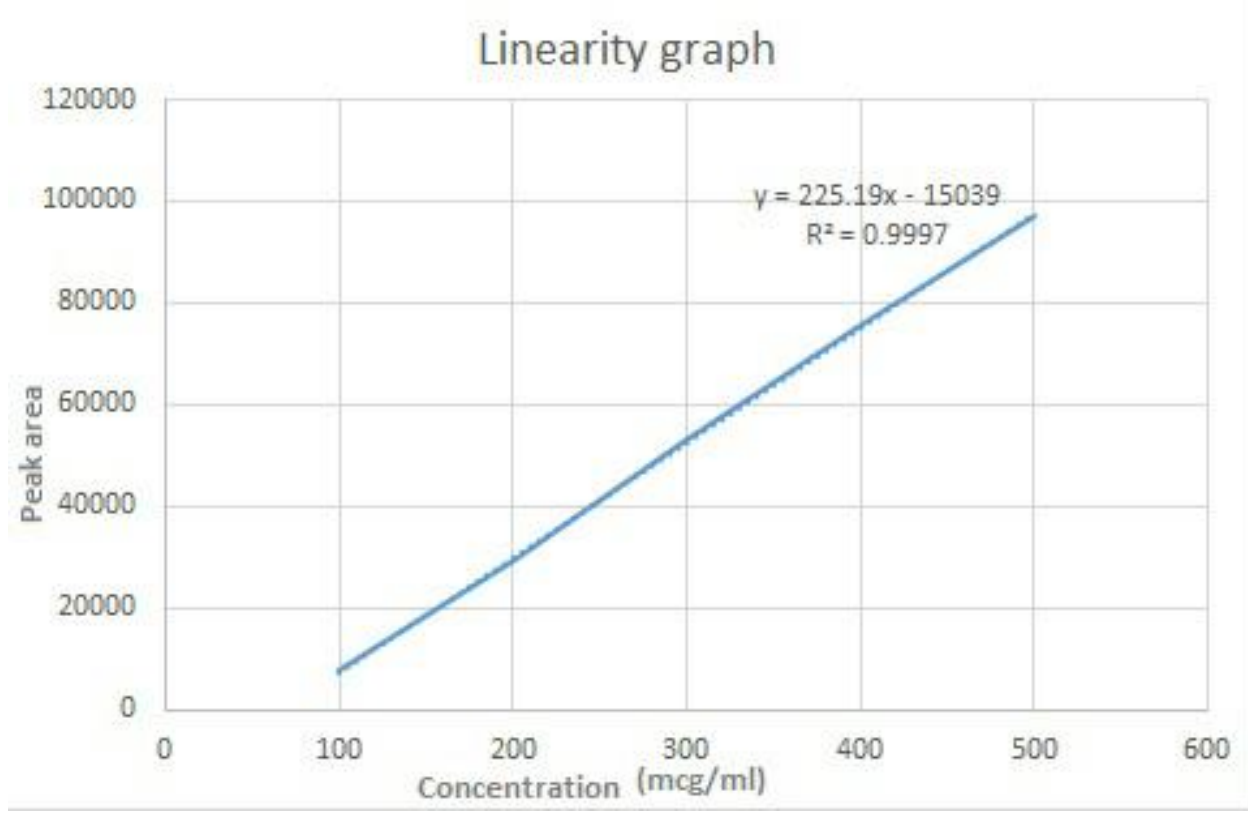

ACCURACY:

The accuracy of the method was verified by means of recovery assay. This was analyzed by spiking the sample with standard solution. The results of the study are reported in the Table.2. The average recovery obtained for lauric was found to be 99.2 to 100.43 .

Table 2: Recovery studies of the method

\begin{tabular}{|c|c|c|c|c|c|c|c|c|}
\hline $\begin{array}{c}\% \\
\text { recovery } \\
\text { level }\end{array}$ & $\begin{array}{c}\text { Amt of drug } \\
\text { taken from } \\
\text { sample }(\mu \mathrm{g} / \mathrm{ml})\end{array}$ & $\begin{array}{c}\text { Amt of } \\
\text { standard } \\
\text { drug taken } \\
(\mu \mathrm{g} / \mathrm{ml})\end{array}$ & $\begin{array}{c}\text { Total } \\
\text { amount of } \\
\text { drug } \\
(\mu \mathrm{g} / \mathrm{ml})\end{array}$ & $\begin{array}{l}\text { Total amt of } \\
\text { drug } \\
\text { recovered } \\
(\mu \mathrm{g} / \mathrm{ml})\end{array}$ & \% recovery & Mean & $\begin{array}{c}\text { Std } \\
\text { deviatio } \\
\text { n }\end{array}$ & \% RSD \\
\hline \multirow[t]{3}{*}{50} & \multirow[t]{3}{*}{200} & \multirow[t]{3}{*}{100} & \multirow[t]{3}{*}{300} & 298.4 & 99.2 & \multirow[t]{3}{*}{99.2} & \multirow[t]{3}{*}{0.9} & \multirow[t]{3}{*}{0.907} \\
\hline & & & & 300.2 & 100.1 & & & \\
\hline & & & & 296.6 & 98.3 & & & \\
\hline \multirow[t]{3}{*}{100} & \multirow[t]{3}{*}{200} & \multirow[t]{3}{*}{200} & \multirow[t]{3}{*}{400} & 402.2 & 101.1 & \multirow[t]{3}{*}{100.12} & \multirow[t]{3}{*}{1.07} & \multirow[t]{3}{*}{1.07} \\
\hline & & & & 397.9 & 98.97 & & & \\
\hline & & & & 400.6 & 100.29 & & & \\
\hline \multirow[t]{3}{*}{150} & \multirow[t]{3}{*}{200} & \multirow[t]{3}{*}{300} & \multirow[t]{3}{*}{500} & 501.2 & 100.59 & \multirow[t]{3}{*}{100.43} & \multirow[t]{3}{*}{1.157} & \multirow[t]{3}{*}{1.152} \\
\hline & & & & 498.4 & 99.2 & & & \\
\hline & & & & 503.1 & 101.52 & & & \\
\hline
\end{tabular}

PRECISION:

The precision of the method was calculated by measured data of single day. Intraday precision was determined by measuring the data in successive days. Both values were expressed in terms of percentage relative standard deviation. The results of the precision studies were shown in Table.3.

Table.3: Precision Data of the proposed method

\begin{tabular}{|c|c|c|}
\hline Sample No & Interday & Intraday \\
\hline 1 & 43183.9 & 46982 \\
\hline 2 & 43236.6 & 47690 \\
\hline 3 & 43765.6 & 46882.2 \\
\hline 4 & 41701.1 & 48520.3 \\
\hline 5 & 42623.7 & 47632.6 \\
\hline 6 & 43778.5 & 47665.6 \\
\hline Mean & 43048.23 & 47562.11 \\
\hline SD & 786.99 & 935.13 \\
\hline RSD & 1.82 & 1.966 \\
\hline
\end{tabular}




\section{LIMIT OF DETECTION (LOD)\& LIMIT OF QUANTITATION (LOQ):}

They can be determined either by signal to noise ratio method or by standard deviation method. In this study we employed standard deviation method. The LOD\&LOQ were determined by using formula $(3.3 \mathrm{X} \rho) / \mathrm{S}$ and $(10 \mathrm{X} \rho) / \mathrm{S}$ respectively. The LOD\&LOQ were found to be $0.385 \& 1.168$ respectively.

\section{Robustness:}

The robustness of the method was set up by changing the following parameters slightly i.e. change in injection temperature, split ratio and initial column temperature. Even though there were change in parameters the \% RSD was found to be less than 2 . The results of the study are shown in Table. 4.

Table.4: Robustness of the method

\begin{tabular}{|c|c|c|c|c|c|}
\hline Parameters & Conditions & Area & Mean & SD & $\%$ RSD \\
\hline \multirow{3}{*}{$\begin{array}{c}\text { Injection } \\
\text { temperature }\end{array}$} & 250 & 35428.5 & & & \\
\hline & 250.2 & 35369.2 & 35318.85 & 41.93 & 0.118 \\
\hline & 249.8 & 36049.7 & 35739.10 & 439.25 & 1.229 \\
\hline \multirow[t]{3}{*}{ Split ratio } & 5 & 36577.6 & & & \\
\hline & 5.2 & 36318.5 & 36448.05 & 183.21 & 0.502 \\
\hline & 4.8 & 36595.4 & 36586.5 & 12.58 & 0.034 \\
\hline \multirow{3}{*}{$\begin{array}{l}\text { Initial column } \\
\text { temperature }\end{array}$} & 100 & 37569.3 & & & \\
\hline & 100.2 & 38183.2 & 37876.25 & 434.09 & 1.146 \\
\hline & 99.8 & 36957.5 & 37263.4 & 432.60 & 1.160 \\
\hline
\end{tabular}

\section{CONCLUSION:}

A GC-FID method was developed for simultaneous analysis of Lauric acid present in pure and commercial coconut oil. Lauric acid is separated by using a ZB-WAX plus column with total run time of $6.42 \mathrm{~min}$. The sample preparation procedure was simple and straightforward with no derivatization required. The method was validated and proved to be specific, precise and accurate for analysis of Lauric acid and related fatty acids. Several other methods were also developed for the estimation of fatty acids by HPLC-ELSD, GC, NMR, HPLC using flouroscent detector, GC-MS, esterification, distillation but major amount of lauric acid content in pure and commercial coconut oil was detected by GC-FID and the method developed is simple and robust method.

Hence it can be employed in testing the purity of coconut oil and determine its lauric acid content

\section{REFERENCE}

[1] Anzaku, A. A. et al. (2017) 'Antibacterial Activity of Lauric Acid on Some Selected Clinical Isolates iMedPub Journals Antibacterial Activity of Lauric Acid on Some Selected Clinical Isolates Lauric acid or systematically dodecanoic acid is saturated', (March 2018). doi: 10.21767/2386-5180.1000170.

[2] Bornscheuer, U. T. (1995) 'Lipase-catalyzed syntheses of monoacylglycerols', 0229(94).

[3] Dayrit, F. M. (2014) 'The Properties of Lauric Acid and Their Significance in Coconut Oil'. doi: 10.1007/s11746-014-2562-7.

[4] Denke, A. and Grundv, M. (2018) 'Comparison on plasma of effects of lauric acid lipids and lipoproteins 13 and and palmitic acid', (February).

[5] Division, N. S. and Associates, E. (2002) 'The Health Benefits of Coconuts \& Coconut Oil', 9(2), pp. 1-8

[6] Elisabeth and HM Temme, Ronald P Mensink, and G. H. (2018) 'Comparison of the effects of diets enriched in lauric , palmitic , or oleic acids on serum lipids and lipoproteins healthy women and men13', (March).

[7] Enig, M. G. (1996) 'Health and Nutritional Benefits from Coconut Oil: An Important Functional Food for the 21st Century'.

[8] FABIAN M. DAYRIT,* OLIVIA ERIN M. BUENAFE, EDWARD T. CHAINANI, A. I. M. S. D. V. and Department (2008) 'and Free Fatty Acids in Coconut ( Cocos nucifera L .) Oil by 31 P NMR Spectroscopy', pp. 5765-5769.

[9] Francois, C. A. et al. (2018) 'Acute effects of dietary fatty acids on the fatty acids of human', (April), pp. 301-308.

[10] Jansen, E. H. J. M. and Flutter, P. De (no date) 'Journal of Liquid Chromatography Determination of Lauric Acid Metabolites in
Peroxisome Proliferation After Derivatization and HPLC Analysis with Fluorimetric Detection', (January 2015), pp. 37-41. doi: 10.1080/10826079208016175.

[11] Loung, F. S., Silalahi, J. and Suryanto, D. (2015) 'Antibacterial activity of Enzymatic hydrolyzed of Virgin Coconut oil and Palm Kernel oil against Staphylococcus aureus, Salmonella thypi and Escherichia coli', 6(2), pp. 628-633.

[12] Moigradean, D. et al. (2013) 'Quantitative identification of fatty acids from walnut and coconut oils using GC-MS method', pp. 2 6.

[13] Odel, F., Siswanta, D. and Nurwening, E. (2016) 'Isolation and Antibacterial Activity Test of Lauric Acid from Crude Coconut Oil ( Cocos nucifera L .)’. Elsevier Ltd., 18(Mcls 2015), pp. 132 140. doi: 10.1016/j.proche.2016.01.021.

[14] Onyeagba, R. A. and Chigbu, O. A. (2006) 'Lauric acid content and inhibitory effect of palm kernel oil on two bacterial isolates and Candida albicans', 5(June), pp. 1045-1047.

[15] Ponphaiboon, J. et al. (2018) 'PT NU', Journal of Chromatography B. Elsevier B.V, p. \#pagerange\#. doi: 10.1016/j.jchromb.2018.09.023

[16] Shilling, M. et al. (2013) 'FULL COMMUNICATIONS Antimicrobial Effects of Virgin Coconut Oil and Its MediumChain Fatty Acids on Clostridium difficile 1', 16(12), pp. 1079 1085. doi: 10.1089/jmf.2012.0303.

[17] Silalahi, J. and Putra, E. D. E. L. U. X. (2018) 'Antibacterial activity of hydrolyzed virgin coconut oil', (February 2014).

[18] St, W. et al. (1988) 'Lipase Immobilized on a Hydrophobic , Microporous Support for the Hydrolysis of Fats 1', 65(6), pp. 917-921.

[19] Thoistrup, T. et al. (2018) 'Fat high in stearic acid favorably affects blood lipids and factor VII coagulant activity in comparison with fats high in palmitic acid or high in myristic and lauric acids13', (February)

[20] Zhang, H., Wang, Z. and Liu, O. (2015) 'Author' s Accepted Manuscript', Journal of Pharmaceutical Analysis. Elsevier. doi 10.1016/j.jpha.2015.01.005. 